\title{
Can Too Few and Too Many Climato-Economic Resources Elevate Blood Pressure? A 120-Nation Study
}

\author{
Mike JL DeJongste ${ }^{1^{*}}$, Reinold OB Gans ${ }^{1}$ and Evert Van de Vliert ${ }^{2}$
}

${ }^{1}$ University of Groningen, University Medical Center, Hanzeplein-19713, GZ Groningen, Netherlands

${ }^{2}$ University of Groningen, Netherlands, Department of Psychology, Grote Kruisstraat 2/l, 9712 TS Groningen, Netherlands

\begin{abstract}
Elevated blood pressure as a major indicator of higher health risks varies considerably around the globe. We examine whether the livability of the environment can account for part of this variation. Overly resource-poor and overly resource-rich countries are expected to be less livable, with elevated blood pressure as a likely result. Male and female populations from 120 countries indeed have higher blood pressures to the extent they have to cope with too few or too many rather than just enough environmental resources. In poorer countries, predominantly located in hotter climes, both genders have higher blood pressures in too difficult-and-expensive environments with more demanding summers or winters (too few resources), than in just-right environments with more temperate summers and winters (optimal resources). In richer countries, predominantly located in colder climes, both genders have higher blood pressures in too easy-and-cheap environments with more temperate winters and summers (too many resources), than in just-right environments with more demanding winters or summers (optimal resources). We conclude that the livability of climatebased demands and wealth-based resources have a heretofore hidden ecological impact on chronic health risks, which may shed novel light also on policies of climate protection and poverty reduction.
\end{abstract}

\section{Keywords}

Blood pressure; Health risks; Global swarming; Poverty reduction; Climato-economic

\section{Introduction}

Populations around the globe differ from one another in blood pressure. According to the [1], average systolic blood pressure currently has its lowest level in South Korea $(119.8 \mathrm{mmHg})$, and its highest peak in Niger $(137.9 \mathrm{mmHg})$. This observation represents an important scholarly issue for practical and theoretical reasons. The practical relevance is that elevated blood pressure increases risks of coronary heart disease, cerebro-vascular accidents, etc. [2-7]. Theoretically, geographic variation in blood pressure raises intriguing questions about ecological antecedents of health risks. Explaining spatial variation in health risks is timely, too, since cross-national survey studies have shown that colder and hotter climates make poorer societies less, but richer societies more, happy and altruistic [8], and that perceptions of ill health, burnout, anxiety and depression increase in poorer countries with more demanding climates but decrease in richer countries with more demanding climates [9]. Apparently, acclimatization-marginal long-term adjustment in anatomy and physiology-falls short as a catchall explanation.

Here, building on these observations, we attempt to cover new ground by seeking to show that the resourcefulness of the place of residence may influence blood pressure levels of entire societies in unobtrusive, unnoticed, and uncomprehend ways. More specifically, we attempt to enrich the rapidly growing literature on psychological geography [10] by providing (a) an innovative perspective on chronically elevated blood pressure as manifesting environmental health risks, (b) a fine-grained explanation of blood pressure levels as a function of climate-based and wealth-based resources, (c) cross-national support for that ecological explanation, and (d) vigorous attempts to falsify that ecological explanation by means of rival predictors of blood pressure. We start to introduce the differential livability of climatoeconomic environments, which is well-documented elsewhere [11], as an ecological antecedent of country-level baselines of blood pressure.

\section{Climato-economic environments}

In colder-than-temperate and hotter-than-temperate environments it is more difficult to satisfy basic existence needs having to do with thermal comfort, nutrition, and health. Indeed, in harsher climates it is harder to maintain a core body temperature of approximately $37^{\circ} \mathrm{C}$, to create protective devices including clothing, shelter structures, and warming or cooling systems, to transform flora and fauna into lifesustaining food, and to safeguard homeostasis and health in still other ways [12-15]. Self-evidently, these persistent public health threats of fewer climate-based resources cannot be properly understood without taking into account compensatory resources available to provide necessities of life including warmth and coolness, food and drink, cure and care. Our species has invented property and money, which help to overcome problems related to climatic survival in a particular place [9,15-16].

Climate-based demands can be under matched, overmatched, or optimally matched, by wealth-based resources of liquid cash and illiquid capital [15]. An optimal amount of climato-economic resources produces less stress than both too few and too many resources. However, stress is a chameleonic construct with widely different connotations in different scientific disciplines, which has no obvious connection with the environment either. We therefore prefer the term

*Corresponding author: Mike JL DeJongste, University of Groningen University Medical Center, Hanzeplein-19713, GZ Groningen, Netherlands, Tel: 31-503616161; E-mail: M.J.L.de.Jongste@UMCG.NL

Received August 06, 2014; Accepted September 05, 2014; Published September 15, 2014

Citation: DeJongste MJL, Gans RO, Vliert EVD. (2014) Can Too Few and Too Many Climato-Economic Resources Elevate Blood Pressure? A 120-Nation Study. J Hypertens 3: 176. doi:10.4172/2167-1095.1000176

Copyright: (c) 2014 DeJongste MJL, et al. This is an open-access article distributed under the terms of the Creative Commons Attribution License, which permits unrestricted use, distribution, and reproduction in any medium, provided the original author and source are credited. 
livability, defined as the extent to which an optimal match between climate-based resources and wealth-based resources is approximated. Too few and too many resources reduce livability. A family of demands-resources theories [11,17-21] predicts that too many threats in overly resource-poor conditions and too few challenges in overly resource-rich conditions both produce more psychosomatic stress than optimally challenging levels of resources do.

Overly resource-poor conditions occur in those poor countries where people have to continuously cope with too threatening colderthan-temperate or hotter-than-temperate climates. Poorer populations in such difficult-and-expensive environments report more unhappiness and health complaints $[8,9,15]$. Less unhappiness and ill-being symptoms are reported in poor countries with temperate climates, such as the Comoros and Honduras, which approximate optimally challenging levels of resources. Overly resource-rich conditions, by contrast, occur in rich countries with too easy-and-cheap environments, such as Barbados and Singapore, where daily life poses fewer challenges in general, and where people need fewer weather-related goods and services in particular. Inhabitants of richer countries are thought to be better off in optimally challenging climates with colder winters or hotter summers to spend the money on. In agreement with this counterintuitive idea, richer populations in harsher-than-temperate climates, such as the Scandinavians, are indeed happier and report fewer and less serious health complaints $[5,8,9,11]$.

These considerations and findings raise the question whether the relations between less climatic resources and ill health in poorer countries, and between more climatic resources and ill health in richer countries, are generalizable from psychic health complaints to somatic health risks manifested in elevated blood pressure. The question is raised also because, more generally, chronically imposed stressors tend to have an adverse impact on a variety of physiologic functions including heart and respiration rate, blood pressure, and gluconeogenesis and lipolysis [21-24]. For overly resource-poor environments, we expected higher blood pressures among inhabitants of poorer countries in less temperate climates with colder-than-temperate winters, hotter-thantemperate summers, or both (Hypothesis 1). For overly resource-rich environments, we expected higher blood pressures among inhabitants of richer countries with more temperate winters or summers, or both (Hypothesis 2).

\section{Methods}

\section{Sample and overview}

The sample consisted of 120 countries for which data on climate and wealth, as well as average systolic blood pressure reported by the World Health Organization were available for analysis (for details, see Appendix). One-sample $t$ tests revealed no indication that these 120 countries do not adequately represent all of the world's 193 countries with respect to more resources in fewer winter demands $(t=-.57$, $p=.28)$, fewer summer demands $(t=-.00, p=.49)$, and greater national wealth $(t=-.54, p=.29)$. The first five years of this century (2000-2005) were chosen as a feasible reference period for all measures used.

The World Health Organization reports blood pressures broken down by gender, enabling us to test the hypotheses twice: first for males and then for females with well-documented differences in blood pressure regulation [25-27]. Male blood pressures and female blood pressures were regressed on standardized indices of winter demands, summer demands, national wealth, and their interactions. The anchor point for tests and illustrations of interaction effects was set at one standard deviation from the mean.

\section{Independent variables: climate and wealth}

The average annual level of climatic temperature is an inaccurate predictor of demands of cold and heat because this average (a) neglects the existence of a livability optimum $\left[4^{\circ} \mathrm{C}\right.$ and $40^{\circ} \mathrm{C}$ both pose problems], (b) overlooks the impact of seasonal variations in cold and heat [small and large differences between winters and summers may have the same average], and (c) is negatively correlated with year-round variations in temperature [higher latitudes have both lower temperatures and larger variations]. An appropriate indicator of climatic demands should rather be based on a biologically optimal point of reference, and should take account of winter and summer deviations from that optimum. In this line of research, $22^{\circ} \mathrm{C}$ (about $72^{\circ} \mathrm{F}$ ) is adopted as a point of reference for optimal climatic livability, not only because $22^{\circ} \mathrm{C}$ is the approximate midpoint of the range of comforTable temperatures [12], but also because existence needs for nutrition and health are met easier in temperate climates varying around $22^{\circ} \mathrm{C}[14]$.

Climatic demands are operationalized across each country's major cities. Winter demands are the sum of the absolute deviations from $22^{\circ} \mathrm{C}$ for the average lowest and highest temperatures in the coldest month, summer demands the sum of the absolute deviations from $22^{\circ} \mathrm{C}$ for the average lowest and highest temperatures in the hottest month (for indices, see [15]. In Mongolia, for example, the lowest and highest temperatures in the coldest month are $-44^{\circ} \mathrm{C}$ and $1^{\circ} \mathrm{C}$; the lowest and highest temperatures in the hottest month are $-6^{\circ} \mathrm{C}$ and $36^{\circ} \mathrm{C}$. Thus, winter demands are $|-44-22|+|1-22|=87$; summer demands are $\mid-6$ $22|+| 36-22 \mid=42$. Criticisms of this measure are concerns about $22^{\circ} \mathrm{C}$ as a questionable point of reference for temperate climate, and the inadequacy of a single index score for large countries spanning multiple climatic subzones. However, somewhat lower or higher reference points than $22^{\circ} \mathrm{C}$ always yield almost identical research results, and adjusting for error-inducing temperature variations within large countries strengthens rather than weakens the effects $[9,15]$. Therefore, the empirical results reported here may be interpreted as conservative estimates of support for the climato-economic hypotheses.

National wealth, itself initially influenced by climate, is expected to later alter the effects of climatic demands on blood pressures. To reduce the skew of its distribution, national wealth was operationalized as the natural logarithm of the purchasing power product per capita in international dollars [28]. Over a 3-year period (1999-2002), its testretest reliability was excellent $(r=.97)$.

\section{Dependent variable: systolic blood pressure}

Using a worldwide network of Reporting Units, the [29] accumulates nationally representative and cross-nationally comparable data on age-standardized systolic blood pressure among males and females in its member states. Painstakingly aiming to meet predefined quality criteria, the World Health Organization standardizes its blood pressure data collection with respect to country-level sampling places and huge sample sizes, timing and ambience (time of year; time of day; room temperature; measurer), equipment used (type of sphygmomanometer; bell or diaphragm; width of cuff), and measurement procedures (posture of subject, arm used, arm circumference, quality control) [30]. The most recently released data are for 2002 and 2005. Over this period, the countries' relative positions on blood pressure remained extremely sTable for both males $(r=.993)$ and females $(r=.995)$, with the consequence that research results for 2002 and 2005 were identical. For the 2005 indicators used here, systolic blood pressure ranged from $113.9 \mathrm{mmHg}$ in Peru to $142.2 \mathrm{mmHg}$ in Lesotho for males, and from $107.8 \mathrm{mmHg}$ in Kenya to $140.4 \mathrm{mmHg}$ in Maldives for females. 


\section{Control variables}

Climatic precipitation, the 30 -year average of rain, hail and snow in $\mathrm{mm}$ [31] was included because precipitation may lower or raise the thermal livability optimum.

Infectious disease burden [32] is a well-known ecological stressor that may directly or indirectly influence our dependent variable of blood pressure.

Early mortality burden (life expectancy multiplied by -1; [28] may well predict life stress manifested as elevated blood pressure in parents. A distinction was made between male early mortality and female early mortality because loss of boys or girls may have different impacts on both parents, or on either mothers or fathers.

Body mass index as a measure of obesity of males and females [29], and as a covariate of blood pressure, also deserves to be controlled for.

Total serum cholesterol level in males and females [29] is another physiological covariate of blood pressure that might confound the results, either alone or in interaction with body mass index.

Societal inequalities put pressure on subordinated classes, and may thus predict societal blood pressures better than climato-economic livability does. This rival explanation was tested three times, for income inequality [28], and for power and gender inequality.

Societal cultures may also confound the results as they covary with climato-economic environments (for evidence, see [9,33]. Collectivistic versus individualistic culture [9], survival oriented versus self-expression oriented culture [34], and political autocracy versus democracy [35] were controlled for.

Consumption habits that influence blood pressure include fat intake (retrieved 12 August 2010 from http://www.fao.org/economic/ess/ publications-studies/statistical-yearbook/en), and alcohol intake and smoking prevalence (both retrieved 12 August 2010 from http://www. who.int/substance_abuse/publications/global_status_report_2004_ overview.pdf).

Control procedure. Salt intake and physical activity had to be left out of consideration due to insufficiency of available data. Also, not all control variables were included in all regression analyses. To minimize list wise deletion of countries for which data were lacking, as well as to minimize violation of the rule of thumb that the number of predictors should be less than 10 percent of the number of cases, we included climatic precipitation, infectious disease burden, early mortality burden, body mass index, and total serum cholesterol level in the initial analysis. Societal inequalities, societal cultures, and consumption habits were controlled for in supplementary analyses.

\section{Results}

\section{Descriptive information}

Country-level means, standard deviations, and intercorrelations of study variables are presented in Table 1 . Note that male blood pressures $(M=126.56$, S.D. $=4.85)$ are higher than female blood pressures $(M=123.11, S . D .=5.51 ; t=11.73, d f=119, p<0.001)$. For the interpretation of the results, it is also important to notice and remind that the 60 poorer countries are located in climatic zones with warmer winters $(t=-4.74, p<.001)$ and hotter summers $(t=2.04, p<.05)$ than the 60 richer countries.

\section{Confirmatory tests}

The results of the initial regression analyses with standardized predictors are reported in Table 2. The fourth and seventh column show that control variables and independent variables together accounted for 37 and 26 percent of the variation in blood pressure of males and females, respectively. Climatic precipitation and the interaction of body mass index and cholesterol level appeared to one-sidedly contribute to blood pressure in male populations but not in female populations (blood pressures were especially lower for male populations with lower weight and higher cholesterol). Winter and summer demands had no effect on female blood pressure, neither alone or in interaction, providing no support for climatic determinism. Similarly, national wealth had no main effects on blood pressure, neither on males nor on females, indicating that blood pressure cannot be attributed to a variety of differences between poorer and richer countries (quantity and quality of diets, financial problems, health system performance, etc.).

Across gender, the two-way interactions of summer demands and national wealth, and the three-way interactions of winter demands, summer demands, and national wealth reached significance, accounting for 10 and 11 percent of the variation in blood pressures of males and females, respectively. The sizes of these climato-economic effects on blood pressure are considerable given the limited chances of biases in the sampling of countries, the sampling of inhabitants, and the sophisticated operationalization of blood pressure measures. The interaction effects are plotted in Figure 1, horizontally broken down for poorer and richer countries, and vertically broken down for male and female populations.

In poorer countries, predominantly located in hotter climes, blood pressures are higher if winters are warm in conjunction with hotter summers $(b=1.08, \mathrm{p}<0.04$ for males; $b=1.56, p<0.02$ for females); for males, blood pressures are also higher if summers are cool in conjunction with colder winters $(b=1.83, p<0.05$ for males; $b=0.16$, $p>0.05$ for females). This confirms Hypothesis 1, that stronger resource-poor environments produce higher blood pressures. In richer countries, predominantly located in colder climes, blood pressures are higher if winters are warm in conjunction with cooler summers ( $b=-2.86, p<0.02$ for males; $b=-3.04, p<0.02$ for females). This confirms Hypothesis 2, that stronger resource-rich environments also produce higher blood pressures.

\section{Disconfirmatory tests}

Because verification and falsification are two sides of the same coin, we additionally sought to destroy the supportive results, replacing the initial control variables in the regression equation with other potential confounders, again for male and female populations separately. To maximize the number of countries in each disconfirmation trial, the hypotheses were retested while including rival predictors on a oneby-one basis. Thus, step by step, we checked the impact of income inequality, power inequality, and gender inequality, cultural collectivism versus individualism, survival versus self-expression culture, political autocracy versus democracy, fat intake, alcohol intake, and smoking prevalence. The results reported in Tables 2 and 3 show that the initial findings, visualized in Figure 1, survived all destructive tests.

\section{Discussion}

The results of this comparative 120-nation study suggest that inhabitants of too difficult-and-expensive and too easy-and-cheap climato-economic environments manifest higher levels of systolic blood pressure and hypertension-related health risks. 'Hypertension is an important worldwide public-health challenge because of its high frequency and concomitant risks of cardiovascular and kidney disease. It has been identified as the leading risk factor for mortality, and is 


\begin{tabular}{|c|c|c|c|c|c|c|c|c|c|c|c|c|c|c|}
\hline Variable & $M$ & S.D. & 1 & 2 & 3 & 4 & 5 & 6 & 7 & 8 & 9 & 10 & 11 & 12 \\
\hline 1. Male blood pressure & 126.56 & 4.85 & & & & & & & & & & & & \\
\hline 2. Female blood pressure & 123.11 & 5.51 & 0.81 & & & & & & & & & & & \\
\hline 3. Climatic precipitation & 113.66 & 87.20 & 0.03 & 0.13 & & & & & & & & & & \\
\hline 4. Infectious diseases & 33.03 & 6.92 & -0.17 & -0.02 & 0.33 & & & & & & & & & \\
\hline 5. Male early mortality & -64.91 & 10.23 & 0.13 & 0.26 & 0.31 & 0.69 & & & & & & & & \\
\hline 6. Female early mortality & -69.65 & 11.50 & 0.07 & 0.22 & 0.33 & 0.72 & 0.98 & & & & & & & \\
\hline 7. Male body mass index & 23.93 & 2.02 & 0.09 & -0.10 & -0.37 & -0.69 & -0.74 & -0.76 & & & & & & \\
\hline 8. Female body mass index & 24.77 & 2.22 & 0.11 & 0.02 & -0.23 & -0.50 & -0.50 & -0.51 & 0.82 & & & & & \\
\hline 9. Male cholesterol level & 4.92 & 0.55 & -0.08 & -0.16 & -0.24 & -0.68 & -0.72 & -0.76 & 0.64 & 0.42 & & & & \\
\hline 10. Female cholesterol level & 4.90 & 0.50 & -0.08 & -0.18 & -0.28 & -0.71 & -0.76 & -0.79 & 0.67 & 0.47 & 0.93 & & & \\
\hline 11. Winter demands & 29.42 & 22.93 & 0.24 & -0.02 & -0.49 & -0.53 & -0.36 & -0.44 & 0.48 & 0.19 & 0.39 & 0.39 & & \\
\hline 12. Summer demands & 24.41 & 6.94 & 0.04 & 0.20 & -0.05 & 0.12 & 0.14 & 0.13 & -0.17 & -0.12 & -0.17 & -0.11 & -0.01 & \\
\hline 13. National wealth & 8.49 & 1.17 & 0.03 & -0.18 & -0.33 & -0.70 & -0.80 & -0.80 & 0.76 & 0.49 & 0.67 & 0.72 & 0.45 & -0.18 \\
\hline
\end{tabular}

Table 1:Means, standard deviations, and intercorrelations of study variables for 120 countries

ranked third as a cause of disability-adjusted life-years' [5]. Though the precise causes of chronically elevated blood pressure are usually unknown, there is ample evidence that chronic stress elevates blood pressure [21-24] Collective life stress due to the broader ecological livability of a people's environment may be yet another case in point. At least, our findings suggest that both too much and too little money to cope with given winters and summers result in livability problems and elevated blood pressure. This relation is robust in that it is generalizable from male populations with relatively high blood pressures to female populations with relatively low blood pressures.

The similarity between how males and females respond physiologically to the resource fullness of their place of residence is impressive, given their well-documented differences in blood pressure regulation [25-27]. In this regard, blood pressure seems to play a broader role as an indicator of environmental survival stress (Figure 1).

In poorer countries, the warm-blooded bodies of both genders are thought to subconsciously register and process that they are especially safe in places with warm winters and cool summers. By contrast, yet likewise, differentially gendered bodies in richer countries appear to register and process that similarly warm winters and cool summers threaten their healthy existence. In addition, male as well as female bodies in richer countries seem to automatically know that hot summers alternated with cold winters are more life-threatening and in need of compensating reactions than hot summers alternated with warm winters. Given that climato-economic survival is a necessary but insufficient condition for genetic survival over time [15,11], it might be interesting to further investigate whether climato-economic livability and stress also producing genetic changes, such as CaMK4 deletion, in order to secure survival of the human species in the long run [36].

Of course, this study is no exception to the rule that every investigation has inherent strength and weaknesses as a result of the methods employed. The strength of a large multi-country sample size came with the weakness that numerous unknown cross-national differences could be responsible for the results (e.g., genetic make up of the population and historical factors other than the climatic and economic past). The fact that several rival predictors were controlled for (e.g., infectious diseases, early mortality, body mass index, cholesterol level, intake of fat and alcohol, and smoking prevalence), does not guarantee that valid inferences were drawn. The strength of mapping somatic pressure for differentially livable climato-economic environments came with the weakness of untested longitudinal causality. The power of using average systolic blood pressure as an objective and unobtrusive measure of climato-economic health risks in a country came with the weakness that experienced health was not measured and analyzed. As a consequence, our hypotheses about blood pressures in overly resource-poor and overly resource-rich environments were successfully tested but not the gist of their psychosomatic rationale. Finally, salt intake and physical activity as relevant precursors of blood pressure had to be left out of consideration.

Unless the weaknesses of this research overrule its strengths, we may conclude that, in agreement with the so-called climato-economic theory of culture $[9,15,11,33]$ the availability of national wealth resources is a determinant of health risks inherent to differentially livable winter-summer configurations. Inhabitants of the poorest countries, predominantly living in tropical zones, run heat-related health risks to the extent that summers are hotter and winters warmer. Accordingly, child labor and infant mortality peak in poor countries with too hot summers and too warm winters (e.g., Central African Republic, Chad, Guinea-Bissau, Niger, and Togo; [15]. These findings may be useful, also for professional practitioners and interventionists. By contrast, inhabitants of richer countries, predominantly living in colder climes, run more climato-economic health risks in temperate climates with warmer winters and cooler summers (e.g., Grenada and Seychelles) than in more challenging just-right environments having hotter summers relieved with warmer winters (e.g., Malaysia and Oman).

All in all, health risks inherent in elevated levels of blood pressure seem to unfold as a curvilinear function of too few, just enough, and 
Citation: DeJongste MJL, Gans RO, Vliert EVD. (2014) Can Too Few and Too Many Climato-Economic Resources Elevate Blood Pressure? A 120-Nation Study. J Hypertens 3: 176. doi:10.4172/2167-1095.1000176

Page 5 of 7

\begin{tabular}{|c|c|c|c|c|c|c|}
\hline \multirow[b]{2}{*}{ Predictors } & \multicolumn{3}{|c|}{ Male blood pressure } & \multicolumn{3}{|c|}{ Female blood pressure } \\
\hline & $b$ & $b$ & $b$ & $b$ & $b$ & $b$ \\
\hline Constant & $127.03^{*-*}$ & $126.18^{\cdots \cdots}$ & 126.02 & $123.54^{*+*}$ & 123.68 & 123.49 \\
\hline Climatic precipitation & 0.26 & 0.51 & $.96^{*}$ & 0.56 & 0.6 & 0.76 \\
\hline Infectious diseases & $-2.41^{+* * *}$ & $-2.57^{*+*}$ & $-2.52^{* * *}$ & $-2.12^{* *}$ & $-2.21^{* *}$ & $-2.70^{+* *+}$ \\
\hline Early mortality & $2.25^{+\ldots+*}$ & $1.54^{*}$ & 1.19 & $2.65^{*+*}$ & $2.27^{*}$ & 1.68 \\
\hline Body mass index (BMI) & & $1.56^{*}$ & 0.95 & & 0.86 & 1.13 \\
\hline Cholesterol level (CL) & & -1.04 & $-1.35^{*}$ & & -0.94 & -0.97 \\
\hline $\mathrm{BMI} \times \mathrm{CL}$ & & $2.17^{* *}$ & $1.98^{* *}$ & & 0.06 & -0.17 \\
\hline Winter demands (WD) & & & $1.09^{*}$ & & & 0.14 \\
\hline Summer demands (SD) & & & -0.38 & & & 0.11 \\
\hline$W D \times S D$ & & & 0.51 & & & 0.79 \\
\hline National wealth (NW) & & & 0.22 & & & -1.02 \\
\hline WD $\times$ NW & & & -0.26 & & & 0.17 \\
\hline$S D \times N W$ & & & $-.99^{* *}$ & & & $-1.10^{*}$ \\
\hline WD $\times$ SD $\times$ NW & & & $.98^{*}$ & & & $1.26^{*}$ \\
\hline$\Delta R^{2}$ & $.14^{* *}$ & $.13^{+* *}$ & $.10^{*}$ & $.13^{*+*}$ & 0.02 & $.11^{*}$ \\
\hline Total $R^{2}$ & $.14^{+*+*}$ & $.27^{* \prime \prime}$ & $.37^{+* *}$ & $.13^{* * *}$ & $.15^{+*+*}$ & $.26^{* *}$ \\
\hline Notes: $N=120$ countries. Reg & cients show & $\begin{array}{r}\text { tandardize } \\
\text { (Co }\end{array}$ & $\begin{array}{l}\text { ghts. Ther } \\
\text { 19). }\end{array}$ & ulticollinec & = 4.5), and & no outlier \\
\hline
\end{tabular}

Table 2: Joint effects of predictors on blood pressures in male and female populations
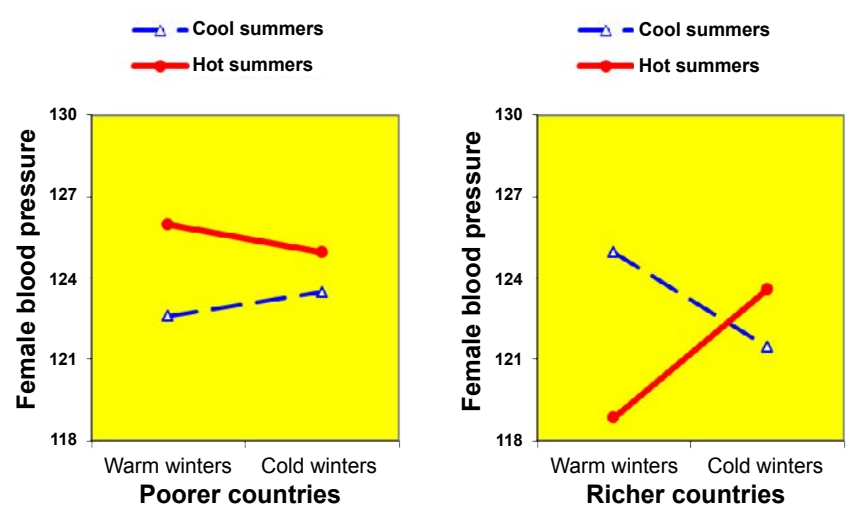

Figure 1: Joint effects of winter demands, summer demands, and nationa wealth on blood pressures in male and female populations

too many climato-economic resources in the place of residence. On closer scrutiny, this curvilinear function is a new incarnation of the classic archetypal relation between optimal stimulation or arousal and pleasantness, subjectively experienced as well being [37,38] and objectively manifested in elevated blood pressure [39]. Health risks may well decrease if climato-economic resources increase, to reach a turning point, beyond which health risks increase again in response to further increases in climato-economic resources. Indeed, this U-curved resources-health relation, which has been observed earlier for mental health problems [8], seems to be generalisable to physiological health reflected in arterial blood pressure.

Our pattern of findings may shed novel light also on two huge threats humanity faces today: global warming and local poverty. If Figure 1 is a valid representation of dynamic relations between differentially livable climato-economic environments and chronic health risks, and reflects causality rather than simultaneity, a manageable degree of global warming may be expected to increase health risks in many poorer countries but to decrease them in many richer countries. What's more, such a modest amount of global warming in conjunction with economic growth may be expected to reduce hypertension-related health risks (this study), health complaints, burnout, anxiety and depression [9], and other public health consequences of climato-economic livability. The world community can perhaps use these new insights to especially 
Citation: DeJongste MJL, Gans RO, Vliert EVD. (2014) Can Too Few and Too Many Climato-Economic Resources Elevate Blood Pressure? A 120-Nation Study. J Hypertens 3: 176. doi:10.4172/2167-1095.1000176

Page 6 of 7

\begin{tabular}{|c|c|c|c|c|c|}
\hline \multirow{3}{*}{ Rival predictor } & \multirow{3}{*}{ Number of Countries } & \multirow{2}{*}{\multicolumn{2}{|c|}{$\begin{array}{l}\text { Male blood pressure } \\
\text { Predicted variance (\%) }\end{array}$}} & \multirow{2}{*}{\multicolumn{2}{|c|}{$\begin{array}{l}\text { Female blood pressure } \\
\text { Predicted variance (\%) }\end{array}$}} \\
\hline & & & & & \\
\hline & & Rival first $^{\mathrm{a}}$ & Rival second ${ }^{b}$ & Rival first ${ }^{a}$ & Rival secondb \\
\hline \multicolumn{6}{|l|}{ Societal inequalities } \\
\hline income inequality & 87 & $3+19^{* *}$ & $22^{* *}+0$ & $0+21^{* *}$ & $20^{* *}+1$ \\
\hline power inequality & 47 & $5+32^{* *}$ & $36^{* \star}+1$ & $0+26^{*}$ & $25^{*}+1$ \\
\hline gender inequality & 47 & $2+36^{\star *}$ & $36^{\star *}+2$ & $4+24$ & $25^{*}+3$ \\
\hline \multicolumn{6}{|l|}{ Societal cultures } \\
\hline Collectivism vs. individualism & 84 & $1+22^{* *}$ & $23^{* *}+0$ & $3+14$ & $16^{*}+1$ \\
\hline Survival vs. self-expression & 51 & $4+30^{* *}$ & $29^{*}+5$ & $16^{\star *}+15$ & $25^{*}+6$ \\
\hline Political autocracy vs. democracy & 120 & $5^{*}+12^{*}$ & $15^{\star *}+2$ & $0+13^{*}$ & $12^{*}+1$ \\
\hline \multicolumn{6}{|l|}{ Consumption habits } \\
\hline Fat intake & 112 & $3+12^{*}$ & $14^{*}+1$ & $0+12^{*}$ & $11^{*}+1$ \\
\hline Alcohol intake & 119 & $5^{*}+12^{*}$ & $15^{* *}+2$ & $0+14^{*}$ & $12^{*}+2$ \\
\hline Smoking prevalence & 101 & $0+18^{* *}$ & $17^{* *}+1$ & $0+12$ & $12+0$ \\
\hline
\end{tabular}

Table 3: Rival predictors of blood pressures in male and female populations

promote the physical and mental health of people carving out a living in particularly stressful climato-economic environments.

\section{Acknowledgements}

We thank Mariët Hagedoorn, Wilmar Schaufeli, and Rudi Westendorp for their insightful comments on draft versions of this article.

\section{References}

1. World Health Organization (2014) Mean systolic blood pressure trends.

2. Psaty BM, Furberg CD, Kuller LH, Cushman M, Savage PJ, et al. (2001) Association between blood pressure level and the risk of myocardial infarction, stroke, and total mortality: The cardiovascular health study. Arch Intern Med 161: $1183-1192$

3. Vasan RS, Larson MG, Leip EP, Evans JC, O'Donnell CJ, et al. (2001) Impact of high-normal blood pressure on the risk of cardiovascular disease. NEJM 345 1291-1297.

4. Birkenhager W, Robertson JI, Zanchetti A (2004). Handbook of hypertension: Hypertension in the twentieth century: Concepts and achievements. Amsterdam, the Netherlands, Elsevier.

5. Kearney PM, Whelton M, Reynolds K, Muntner P, Whelton P K, et al. (2005) Global burden of hypertension: Analysis of worldwide data The Lancet 365: 217-223

6. Yusuf S, Hawken S, Ounpuu S, Dans T, Avezum A, et al. (2005) Effect of potentially modifiable risk factors associated with myocardial infarction in 52 countries (the INTERHEART study): Case-control study. The Lancet 364: $937-$ 952.

7. Santulli G (2013) Epidemiology of cardiovascular disease in the 21st century: Updated numbers and updated facts. JCVD 1: 1-2.

8. Van de Vliert E, Huang X, Parker PM (2004) Do colder and hotter climates make richer societies more, but poorer societies less, happy and altruistic? Journal of Environmental Psychology 24: 17-30.

9. Fischer R, Van de Vliert E (2011) Does climate undermine subjective well-being A 58-nation study Personality and Social Psychology Bulletin 37: 1031-1041.

10. Rentfrow PJ (2014) Geographical psychology: Exploring the interaction of environment and behavior. American Psychological Association Washington DC

11. Van de Vliert E (2013) Climato-economic habitats support patterns of human needs, stresses, and freedoms. Behav Brain Sci 36: 465-521.

12. Parsons KC (2003) Human thermal environments: The effects of hot, moderate and cold environments on human health, comfort and performance Taylor and Francis London

13. Rehdanz K Maddison D (2005) Climate and happiness. Ecological Economics 52: $111-125$.

14. Tavassoli N, Wyer RS, Chiu C, Hong Y (2009) Climate, psychological homeostasis, and individual behaviors across cultures Understanding culture: Theory, research, and application. New York: Psychology Press 211-221.
15. Van de Vliert E (2009) Climate affluence, and culture. New York Cambridge University Press.

16. Bandura A, (1997) Self-efficacy: The exercise of control. Freeman New York

17. Lazarus RS, Folkman S (1984) Stress, appraisal and coping. New York: Springer.

18. LePine JA, LePine MA, Jackson CL (2004) Challenge and hindrance stress: Relationships with exhaustion, motivation to learn, and learning performance. Journal of Applied Psychology 89: 883-891.

19. Levi L (1981) Preventing work stress. Reading MA: Addison-Wesley

20. Skinner N, Brewer N (2002) The dynamics of threat and challenge appraisals prior to stressful achievement events. J Pers Soc Psychol 83: 678-692.

21. Chrousos GP, Gold PW (1992) The concepts of stress system disorders: Overview of behavioral and physical homeostasis JAMA 267: 1244-1252.

22. Kyrou I, Chrousos GP, Tsigos C (2006) Stress, visceral obesity, and metabolic complications. Annals of the New York Academy of Sciences 1083: 77-110.

23. Esler M, Eikelis N, Schlaich M, Lambert G, Alvarenga M, et al. (2008) Chronic mental stress is a cause of essential hypertension Presence of biological markers of stress. Clinical and Experimental Pharmacology and Physiology 35: 498-502.

24. Sparrenberger F, Cichelero FT, Ascoli AM, Fonseca FP, et al. (2009) Does psychosocial stress causes hypertension? A systematic review of observational studies. J Hum Hypertens 23: 12-19.

25. Sevre K, Lefrandt JD, Nordby G, Os I, Mulder M, et al. (2001) Autonomic function in hypertensive and normotensive subjects: The importance of gender. Hypertension 37: 1351-1356.

26. Khalil RA (2005) Sex hormones as potential modulators of vascular function in hypertension. Hypertension 46: 249-254.

27. Fu Q, Vongpatanasin W, Levine BD (2008) Neural and no neural mechanisms for sex differences in elderly hypertension: Can exercise training help Hypertension 52: 787-794.

28. United Nations Development Programme Human development report (2004) New York: Oxford University Press.

29. World Health Organization (2005) WHO global infobase: Blood pressure mean

30. World Health Organization (2010) Quality assessment of blood pressure data in the WHO MONICA project.

31. Parker PM (1997) National cultures of the world: A statistical reference Westport, СT: Addison-Wesley.

32. Fincher CL, Thornhill R, Murray DR, Schaller M (2008) Pathogen prevalence predicts human cross-cultural variability in individualism collectivism. Proceedings of the Royal Society 275: 1279-1285.

33. Van de Vliert E, Postmes T (2012) Climato-economic livability predicts societa collectivism and political autocracy better than parasitic stress does. Behav Brain Sci 35: 94-95. 
Citation: DeJongste MJL, Gans RO, Vliert EVD. (2014) Can Too Few and Too Many Climato-Economic Resources Elevate Blood Pressure? A 120-Nation Study. J Hypertens 3: 176. doi:10.4172/2167-1095.1000176

Page 7 of 7

34. World Values Surveys, 2005 (2005).

35. Pemstein D, Meserve SA, Melton J (2010) Democratic compromise: A latent variable analysis of ten measures of regime type.

36. Santulli G, Ciplolletta E, Sorriento D (2012) CaMK4 gene deletion induces hypertension. J Am Heart Assoc 1: e001081.
37. Wundt W (1893) Grundzüge der physiologischen psychologie, Leipzig, Engelman Germany.

38. Yerkes RM, Dodson JD (1908) The relation of strength of stimulus to rapidity of habit formation. J Comp Neur 18: 459-482.

39. Blanch flower DG, Oswald AJ (2008) Hypertension and happiness across nations. Journal of Health Economics, 27: 218-233. 